\title{
HOSPITALIDADE E INTEGRAÇÃO NA ARQUITETURA DO COMUM NAS SOCIABILIDADES ESCOLARES
}

\author{
José Manuel Resende' \\ (D) Luís Gouveia" \\ D David Beirante ${ }^{\prime \prime}$ \\ l Universidade de Évora, Évora, Portugal; josemenator@gmail.com \\ " Universidade Nova de Lisboa, Lisboa, Portugal; Icgouveia86@gmail.com \\ I" Universidade Nova de Lisboa, Lisboa, Portugal; dbeirante@gmail.com
}

\section{Resumo}

O presente artigo parte de dados recolhidos de uma pesquisa centrada nas sociabilidades escolares, pretendendo-se, na esteira de uma sociologia dos envolvimentos e comunalidades, trazer à luz outros ângulos da justiça escolar e do fazer o comum na escola. É, concretamente, mobilizada uma técnica designada por questionário por cenários, em que, a partir de uma narrativa de carácter dilemático, pretende-se aceder aos sentidos morais evidenciados por alunos inquiridos. Analisamos em particular as inquietações em torno do respeito, reconhecimento, hospitalidade e decência trazidas à colação por esses atores nas interações e nos juízos críticos produzidos - juízos esses que transcendem leituras meramente feitas a partir dos dispositivos formais reguladores das condutas no espaço escolar.
\end{abstract}

SOCIABILIDADE • JUSTIÇA • ESCOLAS • ALUNOS

\section{HOSPITALITY AND INTEGRATION IN THE MAKING OF THE COMMON IN SCHOOL SOCIABILITY}

\begin{abstract}
This article is based on data collected from a research project centred on school sociability, aiming, through a sociology of engagements and commonalities, to shed light on other angles of school justice and the making of the common in the school territory. Specifically, a technique termed scenario survey is mobilized, in which, based on a dilemmatic narrative, the intention is to access the moral meanings evidenced by the inquired students. We analysed particularly their inquietude around respect, recognition, hospitality and decency brought up by these actors in their interactions and critical judgments - judgments that transcend interpretations merely based on the formal governing devices of actor's conduct in the school space.
\end{abstract}

SOCIABILITY • JUSTICE • SCHOOLS • STUDENTS 


\section{HOSPITALIDAD E INTEGRACIÓN EN LA ARQUITECTURA DE LO COMÚN EN LAS SOCIABILIDADES ESCOLARES}

\section{Resumen}

El presente artículo parte de los datos recogidos de una pesquisa centrada en las sociabilidades escolares, pretendiéndose, en la huella de una sociología de las participaciones y comunidades, traer a la luz otros ángulos de la justicia escolar y del quehacer habitual en la escuela. Es, concretamente, movilizada una técnica designada por cuestionario por situaciones, en que, a partir de una narrativa de carácter dilemático, se pretende acceder a los sentidos morales evidenciados por alumnos inquiridos. Analizamos en particular las preocupaciones en torno del respeto, reconocimiento, hospitalidad y decencia planteadas por esos actores en las interacciones y en los juicios críticos producidos - juicios esos que transcienden lecturas meramente hechas a partir de los dispositivos formales reguladores de las conductas en el espacio escolar.

SOCIABILIDAD • JUSTICIA • ESCUELAS • ALUMNOS

\section{HOSPITALITE ET INTEGRATION DANS L'ARCHITECTURE DU COMMUN DES SOCIABILITES SCOLAIRES}

\section{Résumé}

Cet article part des données d'une recherche axée sur les sociabilités scolaires. Dans le sillage d'une sociologie des engagements et des communalités, il s'agit de mettre en lumière d'autres aspects de la justice scolaire et du faire commun en milieu scolaire. Concrètement, à l'aide d'une technique denommée questionnaire par scénarios, à partir d'un récit à caractère dilemmatique, on vise à accéder aux significations morales mises en évidence par les étudiants interrogés. Nous analysons en particulier les préoccupations relatives au respect, à la reconnaissance, à l'hospitalité et à la décence soulevées par ces acteurs dans leurs interactions et leurs jugements critiques, jugements transcendant les lectures qui sont faites uniquement à partir des dispositifs formels régissant les conduites dans l'espace scolaire.

\section{SOCIABILITÉ • JUSTICE • ÉCOLES • ÉLÈVES}




\section{SOBRE AS SOCIABILIDADES ESCOLARES À LUPA DAS OPERAÇÕES CRIITICAS DO ESTUDANTADO}

Adentrar em um qualquer estabelecimento de ensino público tem sido uma elevada colheita de experiências múltiplas. O ato de adentramento nos territórios escolares teve o seu início em 2004, no quadro de um projeto de pesquisa construído para discutir sociologicamente como a educação para a cidadania fez a sua entrada na escola no quadro das políticas e ações públicas que visam a orientar os processos de escolarização.

Na verdade, nos idos anos 90 do século passado, os dirigentes políticos do Ministério da Educação de Portugal manifestaram-se preocupados pelo desinteresse dos adolescentes e jovens sobre as questões políticas. ${ }^{1} \mathrm{O}$ conhecimento das medidas desse desapego foi-lhes dado pelos resultados de inúmeros inquéritos por questionários construídos no país ou por instâncias da União Europeia por essa altura que visavam a ter uma noção a mais próxima possível da realidade do tipo de vinculação ou desvinculação dos adolescentes e jovens ao fenómeno político. A maior preocupação dos responsáveis por essas técnicas de observação e pela sua aplicação é de, através dos seus resultados, aferir o grau da qualidade da democracia. E, por aqueles resultados, esse grau não é muito positivo. Uma ampla franja dos jovens e adolescentes são abstencionistas porque não participam, votando, nos atos eleitorais; entre os que na altura já trabalhavam, uma elevada percentagem não estava sindicalizada; muitos estavam alheados das causas públicas, etc. Isto é, o envolvimento político das gerações mais novas dá nota de uma ausência de compromisso destes com a atividade política em ação e frequente.

Diante dessa inquietação geral, desde 2004, o nosso intuito tem sido o de procurar descobrir a gramática de razões desse desinteresse transformado em problema público. De acordo com dados trazidos pela sociologia política à época, mostra-se "evidência empírica suficiente sobre a relação dos jovens com a política” (RESENDE; DIONÍSIO, 2005, p. 673). ${ }^{2}$ No entanto, o afastamento formal dos adolescentes e jovens das questões políticas é contrabalançado por outros engajamentos não convencionados, isto é, não formatados de acordo com os cânones da participação democrática oficial. Ora, este outro lado do envolvimento político tem sido o nosso achado nos sucessivos mergulhos nos espaços escolares ao longo dos últimos 15 anos.

O filão investigativo atrás referido, ressignificado em uma mudança dos sentidos da forma de engajamento político dos adolescentes e jovens, tem-nos obrigado a alargar o espaço da ação pública desses seres. Já não somente se encontram acantonados a uma definição institucional de implicação democrática, como, por exemplo, os graus de abstencionismo eleitoral, ou a militância política em partidos ou em outras organizações constituídas para o efeito, para tomarmos também a sua vinculação na ação pública em movimentos inorgânicos, por vezes mais episódicos, ou os seus envolvimentos em causas públicas mais recentes, como a defesa dos animais, do ambiente, em favor da vida ou da despenalização do aborto, pelo ou contra o casamento homossexual, a favor ou em oposição à adoção por casais do mesmo género, etc.

Tem sido por essa entrada que se tem estado a olhar as sociabilidades escolares. No sentido de ensaiar, desde o início das pesquisas, qual o melhor insight, isto é, qual o melhor discernimento sociológico para captar as modalidades atuantes dos adolescentes e jovens na escola em tudo aquilo que diga respeito às suas vinculações nas discussões de questões de caráter público, a pegada mais adequada, porque mais promissora, tem sido a análise de como são feitas as sociabilidades escolares, quer entre pares, quer entre as figuras estatutariamente categorizadas como alunos, quer entre estes e os seus professores. É

1 Cf. os documentos que em certa medida apoiaram a aplicação desta ação pública do Ministério da Educação e que são foram por nós consultados na altura, entre 2004 e 2007: Eurydice (2005); Decretos-leis n. 6/2001 e n. 209/2002; Pureza et al. (2001).

2 Nesta relação dá-se conta, nomeadamente, de um "absentismo eleitoral particularmente marcante nas camadas juvenis, menor identificação com os partidos políticos (Freire e Magalhães, 2002, p. 139) -, [mas] não menos certo é o facto de que é nos perfis mais juvenis que as formas não convencionadas de participação (Viegas e Faria, 2004, p. 245) adquirem um crescimento bem expressivo" (RESENDE; DIONISIO, 2005, p. 673). 
através delas que se tem interrogado como a socialização política tem sido operada nos estabelecimentos de ensino onde ocorre a escolarização do Ensino Secundário público (Ensino Médio, no Brasil).

Fazer luz das operações críticas é dar voz aos alunos, mas nas suas figuras de adolescentes e jovens. Essa tem sido outra novidade dos nossos estudos. Ao trazer para o centro das indagações sociológicas quais têm sido os seus juízos sobre questões ligadas a situações, momentos, ocorrências que os alunos consideram como injustas, isto é, assuntos que estes dão a conhecer, de modo visível ou de uma maneira delatória (o chibatar escolar produzido pelo chibo - o delator que está invisibilizado), os arranjos das sociabilidades têm-se constituído como a melhor maneira para compreender os sentidos das operações críticas desses seres, que na transição do Ensino Básico - Fundamental - para o Ensino Secundário - Médio - estão a percorrer o arco temporal que vai do fim da adolescência ao início da idade juvenil.

É justamente nessa transição etária que se faz a passagem para o último ciclo das aprendizagens em uma escolarização que o Estado determina como obrigatória. É por isso que essa mudança - etária e de ciclo da escolarização - tem sido um momento interessante para perscrutar quais os sentidos das suas faculdades críticas a propósito de problemas que os alunos nos anunciam, quer nas conversas exploratórias tidas com eles, quer nas entrevistas semidiretivas que nos têm dado. Nas nossas convivências comuns, que ultrapassam os simples tempos das trocas de palavras formais ou informais, as nossas observações capturam modalidades de ação individuais ou coletivas que são suportadas por um conjunto de equipamentos que eles manipulam constantemente na escola: os telemóveis - celulares -, os computadores portáteis - laptops - e outros objetos similares que são, em certo sentido, artefactos que medeiam, ou mesmo interferem com as sociabilidades entre pares, e outras com os adultos, os seus professores ou os técnicos auxiliares de educação, ou ainda os psicólogos, animadores socioeducativos ou outros mediadores culturais que trabalham com eles na escola. Ora, é por esses manufactos que são utilizados com destreza pelos alunos que os docentes têm estado a assinalar a entrada das indústrias culturais nos estabelecimentos de ensino, e manifestam que a sua chegada produz tensões agudas entre as aprendizagens curriculares e os saberes apropriados a partir das plataformas da internet. E tem sido através dos seus usos sociais que temos verificado a sua importância nos seus envolvimentos sociáveis, por vezes tensos, se não mesmo conflituosos, tanto com os colegas e aqueles que qualificam como amigos, quer com os seres mais velhos e que se apresentam com outros estatutos entre muros.

Daquilo que esses seres, nessa transição etária e de ciclo de aprendizagem, têm sido capazes de fazer, a comunalidade escolar em múltiplas vozes tem sido a nossa bússola nas sucessivas pesquisas realizadas. E, se num primeiro tempo o propósito é apreender como a socialização política é operada através da ação pública de devolver à escola tempos letivos dedicados a trabalhar a educação para a cidadania, em momentos subsequentes, os objetos de pesquisa vão assentando em outras âncoras deixadas entreabertas por essa primeira incursão nos territórios escolares. Na verdade, no primeiro itinerário da pesquisa, a agulha norteadora do nosso questionamento fica encerrado sobretudo no trabalho qualificador que é demandado pela socialização política concebida pelo discernimento dos professores com quem trabalhámos a temática da entrada da educação para a cidadania na escola secundária no dealbar do novo milénio (dos finais dos anos 1990 aos primeiros anos do novo milénio). O curioso é que, ao examinar com os docentes como eles operam, através do ensino, mas também através da convivencialidade com os discentes, o problema da educação para a cidadania na escola, estes levantam outros problemas que são por eles problematizados com o apoio em outros eixos que densificam a análise sobre o que traz o questionamento sobre a formulação de uma educação cidadã ao longo de uma escolarização obrigatória cada vez mais prolongada no tempo.

Os axes que os docentes levantam nas suas indagações sobre as dificuldades e desafios em mobilizar os alunos para discutirem problemas que estes consideram como públicos fazem-nos deslocar a nossa atenção para outros dilemas e disputas que os discentes levantam, como, por exemplo, as desigualdades escolares e de tratamento, as questões da humilhação e os seus juízos sobre outras 
injustiças cometidas durante a sua passagem pela escolarização obrigatória. Ora, esse alargamento de questões densifica em muito a análise sobre as artes de fazer o comum no plural nos estabelecimentos de ensino público em Portugal.

\section{O COMUM NO PLURAL NAS SOCIABILIDADES ESCOLARES ENTRE PARES E ÍMPARES 3}

A instituição escolar constitui ao longo das décadas um objeto central na análise sociológica. Entre a produção (profusa) desenvolvida, e enformada por diferentes programas teórico-metodológicos, surgem como enfoque privilegiado as questões relacionadas com o funcionamento dessa instância, centrando-se nomeadamente nas desigualdades escolares produzidas no seu interior - e nas consequências do ponto de vista das desigualdades sociais (THÉVENOT, 2011). No conjunto de questionamentos que norteiam estes estudos em torno da adequação das políticas de acesso à escolarização, de combate às desigualdades escolares e de cumprimento do projeto de uma escola democrática, pode ser identificado como elemento transversal a todos estes empreendimentos científicos a análise do funcionamento dos sistemas educativos sob o ângulo da meritocracia escolar e igualdade de oportunidades enquanto princípios de justiça centrais para o cumprimento do desiderato de uma escola justa (DUBET, 2004; SCHILLING; ANGELUCCI, 2016).

Contudo, um olhar sobre os juízos críticos produzidos pelos atores no espaço escolar permite-nos dar conta de perceções de injustiça distintas que assumem relevo nas operações críticas que os atores produzem relativamente ao funcionamento do sistema educativo e ao projeto de construção de uma escola democrática. Nomeadamente, um mergulho etnográfico, com enfoque no vocabulário moral subjacente a essas operações de crítica, permite trazer à luz diferentes princípios de justiça evocados a partir de problemas e questionamentos suscitados por experiências que resultam das sociabilidades escolares e que espoletam sentimentos de injustiça (RESENDE, 2010; RESENDE; GOUVEIA, 2013; BOTLER, 2016). As operações de crítica produzidas pelo alunado evidenciam a existência nas escolas de zonas problemáticas e que são originadas por ocorrências que agitam o quotidiano ou situações a partir de ações perpetradas pelos pares e/ou pelos professores.

Com efeito, os juízos que os alunos (mas também os professores) produzem em torno do quotidiano escolar transcendem as questões relacionadas com a igualdade e mérito enquanto princípios de justiça - neste caso, mobilizados nas inquirições relacionadas com os resultados escolares obtidos (na justa distribuição das classificações) ou referentes aos processos de aprendizagem na relação pedagógica com os professores (DUBET, 2009). É, desde logo, a questão do respeito (PHARO, 2001; RAYOU, 1998; RESENDE; GOUVEIA, 2013), enquanto princípio de justiça mobilizado pelos alunos, constrangedor da liberdade de ação dos atores de forma a não infringir o valor imanente reconhecido a cada indivíduo e desligado de contingências de hierarquização entre os diferentes seres.

Essa polarização na ideia de respeito nos juízos produzidos deve ser enquadrada, por sua vez, numa problemática mais abrangente. Com efeito, no contexto das relações dos atores nas instituições contemporâneas, assiste-se a uma moralização da crítica social (ZACCAÏ-REYNERS, 2008; STAVO-DEBAUGE; DELEIXHE; CARLIER, 2018), em que o apelo à semântica do respeito surge em paralelo com a emergência de questões como a da hospitalidade (STAVO-DEBAUGE, 2017), do reconhecimento (HONNETH, 2011) ou da decência (MARGALIT, 1996) quando os atores se pronunciam criticamente sobre o funcionamento das instituições e sobre as formas de fazer o comum.

3 O presente artigo baseia-se em dados empíricos retirados do projeto de investigação financiado pela Fundação para a Ciência e Tecnologia (FCT) e Comissão para a Cidadania e Igualdade de Género (CIG), intitulado "Género, Desigualdade e Humilhação: sentimentos de injustiça nas escolas", aprovado em 2008 com a referência PIHM/GC/0085/2008. A pesquisa decorreu entre 2009 e 2012 
Efetivamente, o acesso aos juízos morais que os alunos constroem, quer na relação entre pares, quer na relação entre ímpares (RAYOU, 1998; RESENDE; GOUVEIA, 2013), permite compreender de que forma tecem as suas sociabilidades no espaço escolar, nas diferentes gramáticas que suportam as suas ações e atuações para fazer o comum na escola - aceder aos conceitos de justiça e lógicas atuantes que orientam a ação dos jovens (RAYOU, 1998; RESENDE; GOUVEIA, 2013), penetrando nos diferentes reportórios de carácter moral e político através das quais os alunos regulam a vida em comum com o conjunto dos atores que povoam o espaço escolar.

Uma técnica pode ser particularmente frutífera para aceder aos quadros morais orientadores da conduta dos alunos no território escolar. Essa técnica de observação é o questionário por cenários (DANIC; DELALANDE; RAYOU, 2006). Numa descrição sucinta dos pressupostos fundamentais dessa técnica, aos inquiridos é apresentada uma narrativa hipotética, de natureza dilemática, suscitando diferentes possíveis juízos morais e políticos estruturados a partir de distintos regimes de envolvimento e gramáticas de comunalidade (BOLTANSKI; THÉVENOT, 2006; THÉVENOT, 2006).

A narrativa é acompanhada de um conjunto de proposições ou hipóteses de saída em face do dilema apresentado tendo em vista a resolução ou remediação da injustiça cometida, sendo os inquiridos convidados a ordenar - da mais injusta à mais justa - as diferentes avaliações que essas proposições encerram. Por fim, é ainda solicitado aos respondentes que concretizem a avaliação que fazem do cenário apresentado através da redação de uma justificação para a escolha da opção de resposta que consideram ser a mais injusta (e objeto de posterior categorização por parte do investigador), fazendo referência direta às referências morais e normativas que estão subjacentes à sua posição.

O cenário em concreto apresentado ${ }^{4}$ centra-se num aluno portador de uma limitação física, cerceadora da sua capacidade de locomoção. Residindo nessa vulnerabilidade a causa, o aluno chega a uma aula depois do toque de entrada, encontrando os restantes colegas já sentados nos respetivos lugares. $\mathrm{O}$ seu atraso (reiterado) para chegar atempadamente à sala de aula - retardando, como consequência, o início da lição -, suscita a intervenção da docente. A admoestação tem lugar perante o resto da turma, e é justamente neste reparo que reside o foco da discórdia protagonizada pelas duas personagens.

\begin{abstract}
Uma professora abre a porta da sala de aula para os seus alunos entrarem. Já com todos os alunos sentados, a professora dirige-se à porta para a fechar, mas repara num aluno seu ainda a encaminhar-se para a sala de aula - o Ricardo, um rapaz que é coxo de uma perna. A professora, então, diz em voz alta: "Caramba, Ricardo! Tu, mais do que ninguém, devias ter o cuidado de ir logo para a sala ainda antes do toque de entrada. Já viste que deixas constantemente toda a turma à tua espera?".
\end{abstract}

Ricardo, perante o reparo da professora, responde: "Eu vou para a aula quando vão os outros; não vejo porque é que tenho que ser diferente.".

De imediato, a professora respondeu: "Veja lá como fala! Não sabe que tem de ser pontual?".

Das soluções expostas em baixo, ordena por ordem crescente, da mais injusta (no7) à mais justa ( $n$-5), colocando apenas uma letra em cada um dos casos.

4 O cenário integra um questionário que é trabalhado no projeto de investigação mencionado na nota de rodapé anterior. Aplicado a alunos a frequentar o 12ano, foram ao todo validados 716 questionários. Numa descrição sucinta da amostragem, o inquérito foi aplicado em seis estabelecimentos de ensino com públicos escolares social e geograficamente contrastantes. A escola A, localizada no centro-norte de Portugal, caracteriza-se pela combinação de alunos oriundos das classes populares ligadas à agricultura e a pequenas empresas, bem como pelas baixas qualificações escolares dos progenitores. Com um perfil de alunos predominantemente oriundos das classes populares, surgem a escola B - situada numa área histórica de Lisboa -, a escola E - num município contíguo à capital do país - e a escola F - situada na sede de um distrito do Interior de Portugal. Com os perfis socialmente mais favorecidos, surgem, por fim, as escolas C e D. A primeira, situada na Central Business District de Lisboa, alberga alunos predominantemente de classe média e média-alta e pais com elevadas qualificações escolares. No caso da escola D, situada num município contíguo à capital, é frequentada por alunos maioritariamente de classe média. 


\begin{abstract}
A. Perante a situação experimentada em aula a professora não devia ter
\end{abstract} feito qualquer comentário.

B. A professora teve razão em fazer o comentário tal como o fez.

C. O comentário da professora devia ter sido feito após a aula, dirigindo-se diretamente ao aluno.

D. O Ricardo devia ter aceitado o comentário sem responder à professora.

E. O comentário da professora foi incorreto e o Ricardo fez bem em responder.

A situação descrita pode ser entendida como constituindo um momento de tensão entre diferentes critérios de justiça, e o diferendo que ela encerra suscita questionamentos do ponto de vista da composição do comum. A narrativa coloca, nomeadamente, os inquiridos perante a dualidade entre, por um lado, o acomodamento da docente na aplicação do regulamento do estabelecimento de ensino, tendo em conta a condição do aluno em questão (neste caso, relativamente ao tempo de entrada na sala de aula); ou, por outro, a perspetiva de igualdade de todos os alunos, cabendo antes ao aluno handicapado a sua acomodação às normas codificadas que regulam a conduta dos atores no espaço escolar - o que implica, como a professora preconiza, deslocar-se mais cedo do que os colegas para a sala de aula. Por outro lado, na avaliação feita da situação surge também a questão da abordagem da parte da professora. A publicitação da vulnerabilidade do aluno que a sua atuação acarreta é igualmente passível de apreciação crítica por parte dos respondentes.

Uma análise das categorias de justificação em torno daquilo que os inquiridos consideram ser mais injusto - sendo a negação de justiça o ponto de partida para aceder aos referenciais morais e normativos em torno das conceções de uma escola justa (BOTLER, 2016) - permite-nos identificar a pluralidade de gramáticas em confronto na forma como o conjunto dos respondentes ajuíza a situação em mãos. As justificações estruturam-se, nomeadamente, em três grandes polos. ${ }^{5}$

Em primeiro lugar, surgem as justificações que se enquadram na categoria Igualdade de tratamento do aluno/Não atitude discriminatória, correspondendo a 36,2\% dos alunos que integram a amostra. Numa perspetiva convergente, $21,1 \%$ preconizam um Tratamento desigual de aluno/Professora deve ser solidária com aluno.

Com enfoque nas questões de justiça relacional, 22,6\% dos alunos mostram-se críticos relativamente à conduta da professora em função do ato de publicitação que ela acarreta (Não publicitação da diferença). De forma convergente, $4,3 \%$ dos alunos da amostra preconizam que a Professora deve falar de outra forma.

Numa perspetiva distinta, 7,6\% coloca-se numa perspetiva cívica de preservação da igualdade dos alunos, alheia a quaisquer particularismos na avaliação da situação (Igualdade de cumprimento das regras por parte do aluno). Por fim, destaque ainda para $4 \%$ dos inquiridos que, numa perspetiva compósita, não deixando de assumir o mesmo posicionamento de igualdade perante as normas codificadas que regulam a conduta dos atores no espaço do estabelecimento de ensino, preconizam também uma abordagem por parte da docente que salvaguarde igualmente uma exposição do aluno perante os seus pares (Não publicitação da diferença do aluno pela professora + Igualdade no cumprimento das regras pelo aluno).

5 Em virtude dos constrangimentos de espaço, por um lado, e da menor representatividade do ponto de vista da proporção de alunos que nelas se enquadram, por outro, cinco categorias são deixadas de fora na exposição feita, remetendo apenas à sua utilização para a análise fatorial apresentada adiante) do presente artigo. São essas categorias: 0 aluno deve responder (1,3\%), A professora devia ter falado de outra forma + Igualdade no cumprimento das regras pelo aluno (1,3\%), Igualdade no tratamento do aluno pela professora + Igualdade no cumprimento das regras pelo aluno ( $1 \%$ ), A professora devia ter falado de outra forma + O aluno deve responder (devia ter falado de outra forma) $(0,3 \%)$, Aceitação que a professora trate de forma desigual o aluno + lgualdade no cumprimento das regras pelo aluno $(0,3 \%)$. 
De forma a analisar em maior profundidade a diversidade de perspetivas em confronto e os contrastes e afinidades que elas encerram entre si, expõe-se de seguida algumas das justificações que integram as categorias mais representativas.

\section{ENTRE A IGUALDADE CÍVICA E A HOSPITALIDADE NO ATENDIMENTO À VULNERABILIDADE}

No caso da categoria Igualdade de tratamento do aluno/Não atitude discriminatória, os juízos que nela se enquadram assentam-se fundamentalmente na contestação daquilo que, à luz da ordem de grandeza cívica, os alunos inquiridos qualificam como um comportamento discriminatório da parte da professora. Os excertos que se seguem ilustram esse ponto de vista.

B. Se estamos numa sociedade onde querem que não haja injustiça e diferenciação entre as pessoas e principalmente numa escola, a professora nunca devia ter dito o que disse.

o Ricardo lá, por ser coxo de uma perna, não iria mais cedo, pois tem direito a "brincar" com os amigos o mesmo tempo, a professora devia ter compreendido o problema dele. (Q96: Género feminino; Escola A; Curso Profissional)

Porque é estúpido o facto do Ricardo ter problema na perna que vai ser tratado menos que os outros. Então! Somos todos iguais, temos todos os mesmos direitos. (Q284: Género feminino; Escola E; Curso Profissional)

Penso que a opção mais injusta foi a $B$, pois a professora deveria ter consciência que para a aluna, a situação em que se encontra não deverá ser algo fácil de lidar, principalmente vendo todos os seus colegas "normais". Existe no comentário da lecionadora um determinado tom discriminatório perante o aluno. Estas foram as principais razões que me levaram a escolher esta opção. (Q261: Género feminino; Escola B; Curso de Ciências e Tecnologias)

Transversal ao conjunto de justificações está a distinção entre alunos como elemento de injustiça na posição assumida pela docente. A “diferenciação" decorrente de uma interpretação cega do regulamento escolar é enquadrada e problematizada pelos inquiridos como uma injustiça intolerável (BREVIGLIERI, 2009), sendo a igualdade que surge como referência moral e horizonte central nos juízos construídos. Na sua classificação sobre o que é justo, a gramática cívica (BOLTASNKI; THÉVENOT, 2006) norteia os juízos desses atores, fundamentando a sensibilidade moral manifestada de forma patente pelos inquiridos de que diferenças de capacidades não legitimam distinções de tratamento ou de direitos.

De resto, na argumentação da crítica relativamente ao que é qualificado como uma ação discriminante - de não reconhecimento do aluno como participante pleno na escola enquanto comunidade - é patente a operação de dessingularização (BOLTANSKI; THÉVENOT, 2006) por parte dos inquiridos, na medida em que o problema é enquadrado como reivindicação de direitos para o coletivo, uma causa comum, distanciada de interesses particulares. É, nomeadamente, a perspetiva de uma sociedade de iguais, sem diferenciação e com os "mesmos direitos" que surge evidenciada enquanto sensibilidade legal e moral cristalizada entre esses atores no decurso da sua socialização (HONNETH, 2011; MOTA, 2009; SCHILLING; ANGELUCCI, 2016) - e do qual o espaço escolar não está apartado.

Ora, a mesma gramática cívica pode surgir mobilizada de forma distinta no caso dos juízos que se inserem na categoria A professora deve tratar de forma desigual o aluno/deve ser solidária. Neste caso, a perspetiva de igualdade cívica surge articulada com a gramática da hospitalidade (STAVO-DEBAUGE, 2017) nos entendimentos expressos em torno do funcionamento da instituição escolar. É o caso das perspetivas desenvolvidas por outros inquiridos. 
A professora sabendo que o Ricardo era coxo devia ser mais tolerante com a situação dele e se achava que Ihe devia dizer alguma coisa dizia em privado para o Ricardo não se sentir humilhado. (Q154: Género feminino; Escola D; Curso de Línguas e Humanidades)

Pois pelo aluno ser deficiente a professora deveria ter mais paciência e esperar pelo aluno. (Q162: Género feminino; Escola D; Curso de Artes Visuais)

A professora devia ter falado com o aluno com maior compreensão e respeito, pois, o pobre aluno não tem culpa de ser coxo (ou se calhar até tem, mas de qualquer maneira é coxo) e a professora deve-lhe, obviamente, dar um desconto maior que aos outros alunos dada a sua deficiência. (Q172: Género masculino; Escola D; Curso de Artes Visuais)

Ressalta desse conjunto de juízos a mobilização da paciência, a tolerância e a compreensão como categorias morais na abordagem à situação e nas denúncias da inospitalidade - sendo evocada a indulgência por parte da docente enquanto competência de acolhimento (STAVO-DEBAUGE, 2014) e consequente suspensão da expressão da crítica a partir de julgamentos gerais. Se a questão da hospitalidade nasce da assimetria nas formas de apropriação de espaços, é, nomeadamente, no reconhecimento da diferença e vulnerabilidade - nesse caso, materializado na "deficiência" que o discente em questão evidencia - que é fundamentada a reivindicação de um "desconto maior" a ser concedido pela docente ao aluno, enquanto arranjo hospitaleiro que salvaguarda o "respeito" pela alteridade (em vez de uma integração que exija uma submissão às regras). Tal modalidade permite apaziguar a tensão e, desse modo, a vivência em comum (STAVO-DEBAUGE, 2014).

No quadro de um arranjo entre aquilo que é o interesse do coletivo, a partir do mundo cívico, e o atendimento à diferença - neste caso, decorrente da vulnerabilidade do aluno - outros respondentes não deixam de explicitar a forma como a hospitalidade deve ser operacionalizada pela professora. É o caso do próximo conjunto de justificações.

\begin{abstract}
Eu escolhi a resposta $B$, pois o Ricardo devia receber apoio principalmente dos professores, pois já a escola por vezes tende a ser elitista em relação aos colegas. Assim, a professora tem de ter uma atitude de solidariedade e apoio perante o Ricardo, daí na minha opinião, a professora não devia ter feito qualquer tipo de comentário. (Q9: Género masculino; Escola A; Curso de Ciências e Tecnologias)

Na minha opinião, uma professora minimamente bem educada e com princípios nem se atrevia a dizer o que, devia era olhar para ele com um sorriso, o problema é que há muitas destas pelas escolas do país. (Q502: Género masculino; Escola C; Curso de Ciências Socioeconómicas)

Na minha opinião perante as pessoas que tem deficiências físicas, não devemos tratar da maneira como a tal professora falou, desrespeitou-o e insultou-o. Se eu fosse professora apenas dizia "Bom dia, Ricardo, hoje está bem disposto?” (Q420: Género masculino; Escola E; Curso de Ciências e Tecnologias)
\end{abstract}

Novamente, o que surge aludido é a atitude de "solidariedade", de "apoio" para com o aluno enquanto forma de envolvimento da professora que deve imperar na situação em questão. O seu comentário, pelo carácter inóspito que apresenta, deve sim dar lugar ao "sorriso" como gesto hospitaleiro e ao cumprimento acolhedor do aluno ("Bom dia, Ricardo"), cabendo à docente fechar os olhos, no sentido de uma desatenção civil - um retraimento da crítica (BREVIGLIERI; STAVO-DEBAUGE, 2007), a partir de critérios de julgamento gerais - em relação às falhas, aos atrasos protagonizadas pelo discente. É nesta dinâmica de atitudes que envolve gestos e palavras, mas também silêncios ("não devia ter feito qualquer comentário"), que o acolhimento se materializa (STAVO-DEBAUGE, 2017). 
De resto, o primeiro inquirido releva a sua perspetiva crítica relativamente ao que entende ser uma escola cujo funcionamento enquanto instituição se revela "elitista", distanciada dos atores que a integram enquanto comunidade. É também em articulação com o imperativo cívico de uma escola para todos que exige da parte da docente um envolvimento distinto com o aluno e com a interpretação do regulamento escolar.

Por outro lado, a última inquirida alude igualmente ao efeito que o comentário da professora, no conteúdo e modo como é feito, tem sobre o aluno (“desrespeitou-o e insultou-o"). A conduta, na publicitação que ela acarreta, é percecionada como um insulto moral (SIMIÃO, 2006), atentatória da estima de si. Ora, é justamente a gramática do respeito e negação do reconhecimento, associada à experiência de humilhação (PHARO, 2001; HONNETH, 2011), que adquire particular predominância nos juízos morais e denúncias de injustiça em avaliações feitas por outros alunos na relação entre os seres que povoam o espaço escolar.

\title{
O IMPERATIVO DO RESPEITO E A GRAMÁTICA LIBERAL COMO DISPOSITIVO DE HOSPITALIDADE
}

O enfoque na questão do reconhecimento e do respeito enquanto categorias morais surge de forma vincada nos juízos construídos pelos respondentes que integram a categoria Não publicitação da diferença. Efetivamente, é sobre a dimensão moral da ofensa perpetrada pela professora que a avaliação do cenário incide primordialmente, como ilustra o próximo grupo de justificações:

\begin{abstract}
Na minha opinião o comentário da professora foi desapropriado e devia tê-lo feito depois da aula só com Ricardo. Ricardo é coxo, e já tem complexos suficientes por ser assim e não acho correto da parte da professora uma humilhação perante a turma. (Q302: Género masculino; Escola E; Curso Tecnológico)

A professora não devia ter feito qualquer tipo de comentário porque o rapaz pode sentir-se inferiorizado. (Q152: Género feminino; Escola D; Curso de Línguas e Humanidades)

Apesar de considerar que a professora tem razão em querer que o aluno chegue a horas e que por isso deve vir mais cedo, a forma como as coisas são ditas tem muita importância. O ideal seria que falasse com o aluno com compreensão e respeito. A professora acaba por perder a razão agindo como agiu. (Q50: Género feminino; Escola A; Curso de Ciências e Tecnologias)
\end{abstract}

Na estruturação de ambos os juízos, é patente que o que surge contestado não é a posição da docente relativamente à observação do regulamento, convergindo mesmo de forma expressa alguns dos inquiridos com aquilo que é o juízo da professora. Mas o que é colocado em primeiro plano na avaliação qualificadora que é feita da situação é a ação da docente. A publicitação da vulnerabilidade do aluno que ela acarreta produz um efeito humilhante, afetando o autoentendimento de si próprio (OLIVEIRA, 2008), fazendo-o "sentir-se inferiorizado" no seu valor. É, pois, o "respeito" que surge evocado como gramática orientadora das interações dos atores (PHARO, 2001) enquanto posição prática limitadora da liberdade de ação - um constrangimento de civilidade de forma a não infringir o valor reconhecido a um indivíduo.

Esse princípio constitui um elemento particularmente estruturador dos juízos e das operações críticas dos alunos relativamente aos seres de diferentes grandezas (RAYOU, 1998) - uma polarização evidenciada nos juízos em torno da construção da vida em comum no espaço escolar (RESENDE; GOUVEIA, 2013). De resto, a frase em particular da aluna da escola A - "a forma como as coisas são ditas tem muita importância” - constitui em certa medida a expressão sintetizadora desta regra gramatical que deve ser seguida de modo a que o ator seja reconhecido competente na sua ação (LEMIEUX, 2009). Ilustrativo da centralidade do respeito enquanto princípio que vincula os seres 
independentemente dos diferentes estados de grandeza, a incompetência gramatical evidenciada pela docente tem como consequência que esta, no seu entender, "acaba por perder a razão". Para além do conjunto de direitos e deveres codificados que integram os regulamentos do estabelecimento de ensino, é igualmente o princípio da decência (MARGALIT, 1996) que deve estruturar as regras de convivência entre os membros do espaço escolar, moldando as interações de forma a evitar situações de humilhação e proteger aqueles que se encontram em estado de vulnerabilidade.

Outros alunos, na denúncia do comportamento desrespeitoso da docente, não deixam igualmente de preconizar de que forma a composição do comum pode ser feita atendendo à vulnerabilidade do aluno. É o que ilustra o próximo conjunto de justificações:

\begin{abstract}
A professora humilhou o rapaz em frente da sua turma, não o devia ter feito, pois o rapaz já deve ter problemas de autoestima e estes comentários só vão piorar o estado mental do rapaz. E ele tem todo o direito de chegar atrasado, cada um sabe de si. A professora podia ter deixado a porta aberta e ter ido dar a aula. Assim, quando ele entrasse na sala não incomodava tanto. (Q264: Género feminino; Escola B; Curso de Ciências e Tecnologias)

A professora não teve razão em fazer o comentário tal como fez, pois envergonhou o Ricardo diante de toda a turma. Para além disso, o Ricardo está a prejudicar-se apenas a ele, uma vez que a professora pode começar a aula sem a sua presença. (Q40: Género feminino; Escola A; Curso de Ciências e Tecnologias)
\end{abstract}

Num primeiro nível de análise, o que surge relevado e objeto de censura é a "vergonha" e a afetação da autoestima na apreciação positiva de si mesmo (SIMIÃO, 2006; OLIVEIRA, 2008) que a ação da professora acaba por suscitar no aluno - o efeito humilhante decorrente da publicitação da vulnerabilidade. A dor moral suscitada pela conduta da docente é reconhecida pelos inquiridos enquanto observadores da situação (SIMIÃO, 2006; OLIVEIRA, 2008).

Por outro lado, a particularidade da avaliação que é feita reside no facto de a gramática do reconhecimento (HONNETH, 2011) surgir igualmente articulada por ambas as inquiridas com a gramática liberal enquanto modalidade de fazer o comum: a regra generalizada a todos os alunos, codificada no regulamento, de chegar atempadamente à sala de aula é reduzida, na argumentação, a uma questão de preferência ou escolha individual (ERANTI, 2018; STAVO-DEBAUGE, 2014). Sob a máxima de que cada "cada um sabe de si", atendendo àquilo que são os seus interesses, cabe a cada discente fazer as suas opções individuais - arcando (em exclusivo) com as respetivas consequências.

Como a inquirida da escola B preconiza, o deixar a "porta aberta" da sala de aula por parte da professora possibilita a operacionalização dessa perspetiva liberal, permitindo que o aluno não perturbe o funcionamento da aula aquando da sua chegada e, dessa forma, aquilo que é também o interesse geral (o regular funcionamento das aulas na turma) acaba igualmente salvaguardado. Não podendo a forma escolar prestar-se a todas as deformações do ponto de vista daquilo que são as regras que pautam o seu funcionamento, é mediante essa lógica liberal que é possível, na ótica das duas alunas, encaixar (STAVO-DEBAUGE, 2014) a diferença do aluno, dando o estabelecimento de ensino provas de plasticidade, capacidade de abertura - e, desse modo, solucionando o diferendo em questão. A gramática liberal constitui ela própria, assim, um dispositivo de hospitalidade e de fabricação do comum.

Ora, numa perspetiva estruturada a partir da gramática de reconhecimento estão igualmente os alunos que entendem que A professora deve falar de outra forma. Neste caso, as justificações demarcam-se por enfatizar as exigências morais que recaem sobre os docentes na relação com os alunos. É o caso do próximo conjunto de justificações: 
Devido à posição de respeito e conhecimento da professora deveria partir dela o exemplo.

Ao agir de tal maneira, ela permite que os alunos tratem o colega de uma forma diferente. (Q248: Género feminino; Escola B; Curso Profissional)

Devemos ter cuidado com o que dizemos. Medir as palavras e ter respeito uns pelos outros. (Q159: Género feminino; Escola D; Curso de Línguas e Humanidades)

É claro que o seu comentário foi incorreto. Apenas denigre a sua imagem. Há várias formas de dizer o mesmo. (Q445: Género feminino; Escola C; Curso de Ciências e Tecnologias)

No conjunto das respostas, é a grandeza doméstica da docente, derivada da sua "posição" estatutária no quadro da cadeia de relações entre as diferentes figuras tipificadas que povoam o espaço escolar, que é trazida à colação na avaliação feita por esses respondentes - mas também, agregadamente, a condição de adulto e o "conhecimento" acrescido que decorre dessa condição. Se à docente cabe ser um modelo de conduta para os seres de menor grandeza (os alunos) na ótica das relações interpessoais (devendo "partir dela o exemplo"), é, nessa justa medida, a "imagem" da professora que sai denegrida pela sua conduta - sendo essa inabilidade na sua relação interpessoal com o discente em causa que surge como desqualificadora aos olhos dos respondentes (BOLTANSKI; THÉVENOT, 2006). O respeito, enquanto princípio moral que deve pautar reciprocamente a relação, não apenas entre pares, mas também entre ímpares no espaço escolar, surge evidenciado como prova comum aos diferentes seres, independentemente das posições hierárquicas (RESENDE; GOUVEIA, 2013).

\title{
O ACOLHIMENTO INTEGRADOR E A AUTORIDADE DO PROFESSOR
}

Se as perspetivas anteriores colocam (com diferentes tonalidades) o enfoque na acomodação do funcionamento do estabelecimento de ensino enquanto comunidade à vulnerabilidade do aluno, outros respondentes não deixam de afirmar uma perspetiva inversa. É o caso dos inquiridos que se inserem na categoria Igualdade de cumprimento das regras por parte do aluno. Numa perspetiva distinta a partir da ordem de grandeza cívica, é a igualdade dos alunos perante o regulamento enquanto dispositivo que regula a conduta dos atores no espaço escolar (BOLTANSKI; THÉVENOT, 2006) que surge particularmente vincada. As seguintes justificações ilustram esta perspetiva.

\begin{abstract}
Estar perante uma deficiência física deste tipo não é razão para que haja discriminação positiva, no que toca a chegar atrasado a uma aula. O que o Ricardo deve fazer é ir antes para a sala, pois se os outros alunos se atrasam devido a outros problemas não serão desculpados. (Q440: Género feminino; Escola C; Curso de Ciências e Tecnologias)

O Ricardo não devia responder à professora, pois ela tem razão, se ele tem maior dificuldade em andar deve chegar mais cedo. Ele não tem culpa de ser assim mas ele tem de ser tratado como os outros, pois se a professora não o repreender será injusto para os outros também. (Q325: Género feminino; Escola E; Curso de Artes Visuais)
\end{abstract}

Se em perspetivas anteriores a gramática cívica é evocada para sustentar as denúncias de comportamento discriminatório da docente, no caso destes inquiridos, a mesma gramática surge evocada em sentido distinto. Nomeadamente, é a igualdade cívica de todos os alunos perante o regulamento do estabelecimento de ensino que surge relevada, estando os particularismos colocados de parte e quaisquer formas de "discriminação positiva" são tidas como improcedentes (BOLTANSKI; THÉVENOT, 2006). O não acatamento daquela que é a vontade do coletivo é entendido como favore- 
cedor de divisões e suscetível de gerar arbitrariedade na aplicação dos regulamentos ("será injusto para os outros”). Nessa renúncia ao particular enquanto imperativo moral preconizado, cabe, pois, ao aluno em questão acomodar a sua conduta - dirigindo-se mais cedo para a sala de aula, assegurando, dessa forma, o cumprimento do regulamento do estabelecimento de ensino enquanto dispositivo de equivalência entre todos os alunos. Esse acolhimento integrador, na imposição dos constrangimentos de pertença à escola enquanto comunidade que pressupõe, opõe-se, assim, a lógicas hospitaleiras (STAVO-DEBAUGE, 2017).

Por fim, a questão autoridade surge igualmente entre os alunos cuja perspetiva se enquadra na categoria Não publicitação da diferença do aluno pela professora + Igualdade no cumprimento das regras pelo aluno. Estes juízos caracterizam-se por um entendimento compósito, na medida em que, não deixando de assumir uma perspetiva de acatamento do aluno daquilo que são as regras de funcionamento do espaço escolar, o carácter desrespeitoso no modo como a questão é abordada não deixa de ser integrado na avaliação moral que é feita. É o caso das próximas justificações:

\begin{abstract}
Apesar de a professora ter tido uma atitude na minha perspetiva um pouco indelicada, a verdade é que esta é uma figura de autoridade e como tal o Ricardo não devia ter respondido daquela maneira tendo razão ou não. (Q489: Género feminino; Escola C; Curso de Ciências Socioeconómicas)

Visto que o aluno tem um problema de mobilidade, penso que a professora deveria ter feito um comentário mais cauteloso de maneira a não "ofender"o seu aluno à frente dos outros colegas, mas por outro lado o aluno não deveria ter respondido, pois os alunos nunca devem responder às professoras. (Q522: Género feminino; Escola C; Curso de Artes Visuais)
\end{abstract}

Desses juízos ressalta desde logo a forma como, na articulação de gramáticas, a questão do respeito surge referida de forma menos vincada comparativamente com juízos antecedentes. Isso transparece na própria formulação (eufemística) do problema relativo à publicitação - caracterizando a conduta da docente como "um pouco indelicada" ou preconizando um tratamento "mais cauteloso" do problema, de forma a não "ofender" o aluno. Nesse sentido, se a questão da ofensa como categoria moral associada a formas interpessoais de desrespeito não deixa de ser mobilizada na forma como é ajuizada a conduta da docente e os princípios morais que devem pautar a sua atuação (reconhecendo, assim, a dimensão moral da ocorrência), ela surge, no entanto, em segundo plano.

Por seu turno, é a questão da "autoridade" da professora que, na composição de gramáticas, predomina, devendo a figura aluno, enquanto elemento subalterno nesta cadeia de relações, mostrar-se obediente (BOLTANSKI; THÉVENOT, 2006). Se, em juízos anteriores, é a grandeza da docente que é desqualificada pela humilhação do aluno perpetrada enquanto consequência da sua conduta, neste caso, é já o ato de responder - interpretado como desafio à autoridade - que é objeto da crítica desqualificadora do aluno em causa em ambos os juízos. De resto, a lógica vincadamente doméstica adquire particular expressão no postulado comum a ambas as justificações: o de que "os alunos nunca devem responder às professoras", "tendo razão ou não". 


\section{MAPEAMENTO DA PLURALIDADE DE POSICIONAMENTOS MORAIS}

De modo a compreender como o mosaico de princípios de justiça em jogo se compõe, mas também a relação desses juízos morais com um conjunto de variáveis de caracterização da população estudantil, ${ }^{6}$ procede-se, por fim, a uma análise por correspondências múltiplas. O plano fatorial obtido permite evidenciar nos diferentes quadrantes a pluralidade de quadros de juízos produzidos pelos alunos (e relações de proximidade e oposição entre si), desenhando-se igualmente diferentes perfis a partir dos dados de caracterização social (Figura 1).

\section{FIGURA 1 \\ PLANO FATORIAL}

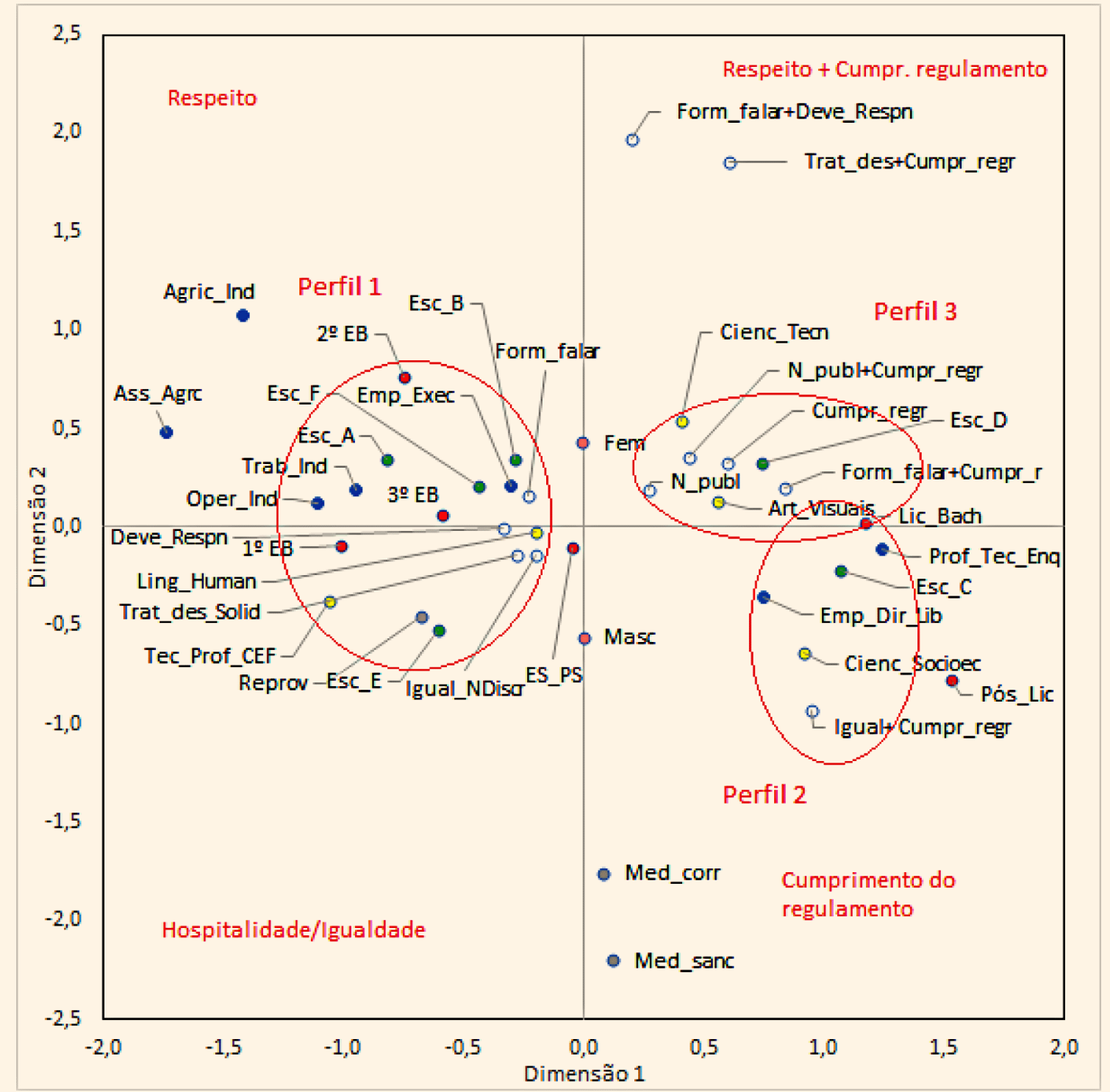

Fonte: Questionário aplicado no âmbito do projeto "Género, Desigualdade e Humilhação: sentimentos de injustiça nas escolas", 2010-12 $(\mathrm{N}=716)$.

6 O plano fatorial é construído com um conjunto de variáveis. Enquanto variáveis ativas, são inseridas todas as 11 categorias de justificação. Em segundo, enquanto variáveis complementares, são selecionadas cinco: "Categoria socioprofissional da mãe", "Habilitações escolares da mãe", "Curso frequentado" (tanto os de carácter científico-humanístico como os de carácter técnico ou profissional). 
No caso do primeiro perfil descortinável (perfil 1), ele é composto pelos juízos que se centram, por um lado, nas questões da justiça relacional (evidenciando o respeito enquanto vocabulário moral), mas também, por outro, no plano da hospitalidade e na crítica a lógicas qualificadas, a partir do mundo cívico, como discriminatórias. ${ }^{7}$

As variáveis de caracterização permitem dar conta do perfil socioeconómico dos discentes cuja avaliação se enquadra nessas categorias. Em primeiro lugar, os inquiridos frequentam os estabelecimentos de ensino da amostra que albergam os públicos escolares menos favorecidos - nomeadamente, as escolas "A", "B", "E" e "F", onde predominam alunos oriundos das classes populares, embora com localizações geográficas contrastantes entre si (ver nota de rodapé 4).

Relativamente às categorias socioprofissionais da mãe, elas surgem associadas aos patamares mais baixos do setor económico secundário - Operários industriais, Trabalhadores independentes e Empregados executantes. O baixo estrato socioprofissional é reforçado pelos níveis de habilitação da mãe, marcados por uma escolaridade completa limitada ao Ensino Básico (Ensino Fundamental). Do ponto de vista do perfil enquanto estudantes, são alunos de Línguas e Humanidades e alunos matriculados nos cursos Técnicos, Profissionais e dos Cursos de Educação e Formação (CEF), vias de ensino que acolhem predominantemente alunos de contextos sociais mais desfavorecidos. De resto, esse perfil caracteriza-se igualmente por alunos que contam, pelo menos, uma reprovação ao longo da sua trajetória escolar.

Esse primeiro grupo surge, no plano fatorial, numa relação de oposição com o perfil 2, que se caracteriza, por sua vez, por uma avaliação do cenário em que é colocado o enfoque no cumprimento das regras de funcionamento, numa perspetiva de igualdade dos atores perante as orientações normativas inscritas no regulamento escolar enquanto dispositivo cívico de regulação das condutas alheado de particularismos. ${ }^{8}$

Neste caso, os variáveis de caracterização revelam já um contexto social de origem distinto. É composto por alunos da escola C, situada no centro de Lisboa e frequentada por alunos de classe média. Relativas às categorias socioprofissionais das mães, integram este grupo as duas categorias mais elevadas. São nomeadamente filhos de Empresários, Dirigentes e Profissionais liberais, bem como de Profissionais técnicos e de enquadramento. Esse panorama socialmente favorecido é igualmente reforçado pelas categorias relativas à variável habilitações académicas da mãe, surgindo a categoria Pós-licenciatura (isto é, detentora de Mestrado ou Doutoramento). Do ponto de vista do curso frequentado, são alunos da via Científico-humanística, nomeadamente no curso de Ciências Socioeconómicas.

Já no caso do perfil 3, é correspondente ao grupo de inquiridos em que a crítica ao carácter inóspito da conduta da professora decorrente da publicitação da vulnerabilidade do aluno é articulada com a perspetiva de igualdade cívica de todos os alunos perante o conjunto de regras codificadas que compõem o regulamento, invalidando dessa forma diferenciações. ${ }^{9}$ Constituindo-se igualmente em oposição ao perfil que avalia a situação preconizando um tratamento diferenciado por parte da docente, integram este perfil os alunos cuja mãe é detentora do grau de Licenciatura/Bacharelato e que frequentam os cursos de Artes Visuais, bem como de Ciências e Tecnologias - sendo esta uma via de ensino que alberga predominantemente contingentes de alunos oriundos de contextos socialmente mais favorecidos.

7 Inserem-se neste grupo, nomeadamente, os alunos cujas justificações integram as categorias: A professora deve falar de outra forma e que o Aluno deve responder; Igualdade no tratamento do aluno/Não atitude discriminatória + Tratamento desigual aluno/Professora solidária aluno.

8 Trata-se da categoria I gualdade no tratamento do aluno pela professora + Igualdade no cumprimento das regras pelo aluno.

9 Nomeadamente, os alunos cujas justificações se inserem nas categorias: Não publicitação da diferença do aluno pela professora + Igualdade no cumprimento das regras pelo aluno; A professora devia ter falado de outra forma + Igualdade no cumprimento das regras pelo aluno; Não publicitação da diferença; e lgualdade de cumprimento das regras pelo aluno. 
Por fim, nota ainda para a variável género. É pertinente relevar que se os alunos do género masculino localizam-se nos quadrantes inferiores do plano fatorial - onde estão os entendimentos relativos à relação perante as regras (discriminação positiva ou igualdade perante as regras) -, no caso das alunas, estas situam-se já nos dois quadrantes superiores, onde predominam as questões de justiça relacional, em que a problemática do respeito e publicitação na conduta da docente surgem mais vincadas nos juízos morais e avaliações qualificadoras feitas.

\section{FAZER O COMUM NO PLURAL: O LUGAR AO RECONHECIMENTO NO RESPEITO PELAS DIFERENÇAS}

Chegados ao fim deste percurso analítico, convém destacar algumas linhas interpretativas a partir do cenário apresentado aos alunos finalistas de seis escolas públicas com Ensino Secundário. No mapeamento que temos produzido a partir dos dados da pesquisa, em outros artigos (RESENDE; GOUVEIA, 2013) tem sido possível mostrar que os alunos de distintas escolas secundárias distribuídas por diferentes regiões do país se vinculam ao comum no plural quando são confrontados com dilemas de uma natureza semelhante àquele que aparece na intriga narrada no cenário. Enredos instigantes como esse, cabe sublinhar, não surgem do acaso. São constitutivos das experiências quotidianas escolares e são constantemente revelados por alunos e docentes quando no decorrer de uma conversa sobre as ambiências escolares nós perguntamos que acontecimentos ali ocorridos os impelem a pensar sobre a sua comunalidade. Na revelação de cenários onde os desiguais são desigualmente tratados, a exposição de ocorrências sobre as diferenças não só não são esquecidas, como se revelam experiências que os afetam com intensidade. E levámos a sério as informações que nos foram trazidas pelos nossos informantes iniciais sobre essas vulnerabilidades físicas e suas consequências.

$\mathrm{E}$, se dúvidas houvesse, o tratamento das informações retiradas das respostas fornecidas pelos inquiridos indicam que a intriga ali exposta, de um lado, não deixou qualquer respondente indiferente, e, do outro lado, o modo como a história os afeta faz mobilizar distintos princípios de justiça elevados na sua generalidade, muitas vezes conjugados com outros regimes de envolvimento da ação de maior proximidade e de familiaridade (THÉVENOT, 2006). E é, em função das modalidades criativas de como compõem as suas tomadas de posição justificativas em face da situação perturbadora, que verificamos que o comum é construído nas escolas, não de modo unilateral, homogéneo, mas de modo plurivocal, isto é, em múltiplas vozes.

O significado sociológico das composições habilmente traçadas pelos respondentes apresenta sentidos profundos, uma vez que as suas experiências decorrentes das sociabilidades escolares combinam uma relativa estabilidade com detonações frequentes, muitas vezes imprevisíveis e outras surpreendentes. E se no bate-boca entre os alunos estão presentes as desigualdades no tratamento derivado do conhecimento dos resultados escolares, isto é, das notas tidas nas provas e trabalhos escolares, a igualdade nos procedimentos de como se devem tratar uns e outros ganha uma notoriedade cada vez mais expansiva, mesmo quando alguns não os expressam de viva voz, por temor ou por carapaças que dificultam a sua exposição corporal para o efeito (BREVIGLIERI, 2007).

Mesmo quando a jocosidade, a piada ou o humor entram fina ou abruptamente nas conversas sobre os problemas que afetam as maneiras de tratamento usadas entre pares, ou como aparece na história, a maneira como um professor trata um determinado colega, amigo ou não, o trato é parte integrante da ementa não planeada do fazer o comum no plural nas escolas portuguesas. Isso significa que essa questão é um problema sensível quer no plano relacional entre os alunos que estudam numa mesma turma e convivem com outros num mesmo recreio, em intervalos que são comuns a todas as turmas, quer entre a categoria discente nas figuras dos adolescentes e dos jovens quando estes se confrontam com professores que, por exemplo, não respondem ao seu cumprimento - "bom dia, stor" ou "boa tarde, stor". 
E só uma minoria dos respondentes aparece preso à formalidade do uso das regras gerais de tratamento incluídas nos regulamentos escolares. E, entre essa reduzida percentagem, há uma proporção deles que não põem debaixo do pano a questão do tratamento, uma vez que se opõem à maneira como a docente reage quando, ao fechar a porta da sala, dá-se conta que Ricardo ainda não tinha entrado. Se as suas normatividades são baseadas na crença da igualdade formal de tratamento que está inscrita nos regulamentos entendidos como convenções cujas regras devem ser aplicadas de igual modo a todos, sem atender a qualquer particularismo, são sensíveis às maneiras destruidoras das estimas de si causadas pelas críticas públicas endereçadas pelos adultos ou por colegas, em muitas situações que compõem o dia a dia de uma escola, a pessoas, nomeadamente às figuras de grandeza pequena (BOLTANSKI; THÉVENOT, 2006), que nas escolas exibem vulnerabilidades, como é o caso do protagonista dessa história.

Na pluralidade das crenças em que se baseiam as suas moralidades, a questão do respeito mútuo entre uns e outros é algo que os confronta permanentemente consigo próprios e nas relações contínuas que mantêm com os colegas, amigos, mas também com os seres de grandeza grande (BOLTANSKI; THÉVENOT, 2006), como é o caso dos professores. É por essa via que entra em força nas escolas o questionamento sobre o reconhecimento perante tudo aquilo que os diferencia como seres humanos, como é o caso do colega que apresenta notoriamente, isto é, na sua corporalidade, uma deficiência motora. Se a maioria dos respondentes assinala que a professora tem de atender a esse pormenor, permitindo que o colega chegue um pouco mais tarde à aula porque, apesar de coxear, tem o direito igual a usufruir do mesmo tempo nos intervalos entre os tempos letivos, é ainda problema maior a exposição pública de que o colega padece da referida deficiência feita às claras pela professora.

O reparo da professora feito em público de que a aula não começa de imediato em virtude do seu atraso permanente, e que a sua demora em entrar na aula é resultante da sua dificuldade em andar depressa, é tido como inaceitável em geral, e em algumas das justificações é considerado como intolerável, isto é, como manifestação pública difícil de suportar. As operações críticas dos alunos em relação à forma de ação da docente na tentativa de se adequar à tensão originada pelo atraso do colega Ricardo demonstram que o lado comum dos discentes (mesmo na sua pluralidade) é muito sensível às consequências das controvérsias que expõem em público a dignidade da humanidade que cada um transporta na sua corporalidade.

Patentear em público, mesmo que por uma maneira não intencionalmente acintosa, a vulnerabilidade de um colega, no caso presente um corpo que exibe uma deficiência motora, é um modo reprovável de estar com todos numa escola, nomeadamente, nas salas de aula, os espaços escolarmente prediletos para aprender a fazer a convivência adequada e ajustada entre uns e outros. Na ligação entre cada um e todos com o seu ambiente, na sala de aula ou fora da sala de aula, o desconforto manifesto que é conferido pelas atribulações norteadas pela publicitação das declarações da parte da docente transforma estes territórios em espaços inabitáveis.

Esta tem sido outra descoberta que vem acontecendo com esses mergulhos sucessivos nos estabelecimentos de ensino ao longo desses últimos 15 anos destinados a examinar como os discentes têm estado ao longo do tempo a confecionar as artes de fazer o comum no plural. Na verdade, os enigmas de como se faz a habitabilidade do espaço escolar têm nos levado a considerar a importância das maneiras como gerações diferentes (em termos etários, mas também em termos da sua antiguidade num dado estabelecimento de ensino) hospedam os seres que ali se matriculam todos os anos.

É por esse arguto sentido que a problemática do respeito mútuo - respeitar é preciso - não pode ser pensada, não é possível ser concebida como problema sociológico, no âmbito das sociabilidades escolares, se não houver uma atenção acrescida em a ligar a outras modalidades do agir criativo que resultam da concretização das consequências dos processos e procedimentos associados ao acolher, ao habitar e ao dotar os espaços escolares como espaços de boa hospedagem, isto é, enquanto espaços onde se investem formas qualitativas de hospitalidade do novo que chega, com as suas 
diferenças manifestamente trazidas pela corporalidade de cada um. São essas ainda as esfinges que nos animam a continuar nesta senda de procurar outros trilhos que estão presentes nos exercícios de governança escolar que têm em vista a construção de uma escola inclusiva. Ora, isto pressupõe que a qualificada boa governança escolar atenda a todos, uma vez que a escola inclusiva não pode derivar para uma escolarização excludente.

É preciso não esquecer que não há escola sem escolarização. Sendo verdadeiro o inverso, dar à escolarização o centro da análise é uma aposta decisiva para nós, uma vez que as sociabilidades escolares não deixam de estabelecer pontes com os formatos tecidos pelas aprendizagens. Importa notar que aqueles formatos dão forma e conteúdo aos atos de escolarizar, concebidos como instrumentos que equipam os alunos dos seus saberes e dos seus conhecimentos, os quais se inscrevem nas suas múltiplas experiências e que os envolvem em muitos dos acontecimentos que povoam a escola.

\section{REFERÊNCIAS}

BOLTANSKI, Luc; THÉVENOT, Laurent. On justification: economies of worth. New Jersey: Princeton University Press, 2006.

BREVIGLIERI, Marc. L’arc expérientiel de l'adolescence: esquive, combine, embrouille, carapace et étincelle... Éducation et Sociétés, v. 1, n. 19, p. 99-113, 2007.

BREVIGLIERI, Marc. L'insupportable. L'excès de proximité, l'atteinte à l'autonomie et le sentiment de violation du privé. In: BREVIGLIERI, Marc; LEFAYE, Claudette; TROM, Danny (org.). Compétences critiques et sens de la justice. Paris: Economica, 2009. p. 125-149.

BREVIGLIERI, Marc; STAVO-DEBAUGE, Joan. L'hypertrophie de l'œil: pour une anthropologie du passant singulier qui s'aventure à découvert. In: CEFAÏ, Daniel; SATURNO, Carole (org.). Itinéraires d'un pragmatiste: Autour d'Isaac Joseph. Paris: Economica, 2007. p. 79-98.

BOTLER, Alice Miriam Happ. Injustiça, conflito e violência: um estudo de caso em escola pública de Recife. Cadernos de Pesquisa, São Paulo, v. 6, n. 161, p. 716-732, jul./set. 2016.

DANIC, Isabelle; DELALANDE, Julie; RAYOU, Patrick. Enquêtes auprès d'enfants et de jeunes: objets, méthodes et terrains de recherche en sciences sociales. Rennes: PU Rennes, 2006.

DUBET, François. L'école des chances: qu’est-ce qu’une école juste? Paris: Le Seuil, 2004.

DUBET, François. Conflits de justice à l'école et au-delà. In: DURU-BELLAT, Marie; MEURET, Denis (org.). Les sentiments de justice à et sur l'école. Bruxelles: De Boeck, 2009. p. 43-55.

ERANTI, Veikko. Engagements, grammars, and the public: from the liberal grammar to individual interests. European Journal of Cultural and Political Sociology, v. 5, n. 1-2, p. 42-65, mar. 2018. doi: 10.1080/23254823.2018.1442733

EURYDICE. A educação para a cidadania nas escolas da Europa. Lisboa: Gabinete de Informação e Avaliação do Sistema Educativo do Ministério da Educação de Portugal, 2005. Disponível em: http://www.oei.es/valores2/cidpt1.pdf. Acesso em: 22 jun. 2020.

HONNETH, Axel. Luta pelo reconhecimento: para uma gramática moral dos conflitos sociais. Lisboa: Edições 70, 2011.

LEMIEUX, Cyril. Le devoir et la grâce. Paris: Economica, 2009.

MARGALIT, Avishaï. The decent society. London: Harvard University Press, 1996.

MOTA, Fábio Reis. Manda quem pode e obedece quem tem juízo? Uma reflexão antropológica sobre disputas e conflitos nos espaços públicos brasileiro e francês. Revista Dilemas: Revista de Estudos de Conflito e Controle Social, Rio de Janeiro, n. 4, p. 107-126, 2009.

OLIVEIRA, Luís Roberto Cardoso de. Existe violência sem agressão moral? Revista Brasileira de Ciências Sociais, v. 23, n. 67, p. 135-146, 2008.

PHARO, Patrick. La logique du respect. Paris: Les Éditions du CERF, 2001.

PORTUGAL. Decreto-Lei n. 6, de 18 de janeiro de 2001. Aprova a reorganização curricular do ensino básico. Diário da República, Lisboa, Portugal, n. 15, 18 jan. 2001. Série I-A. 
PORTUGAL. Decreto-Lei n. 209, de 17 de outubro de 2002. Altera o artigo $13^{\circ}$ e os anexos I, II e III do Decreto-Lei n. 6, de 18 de janeiro de 2001, que estabelece os princípios orientadores da organização e da gestão curricular do ensino básico, bem como da avaliação das aprendizagens e do processo de desenvolvimento do currículo nacional. Diário da República, Lisboa, Portugal, n. 240, 17 out. 2002. Série I-A.

PUREZA, José Manuel; HENRIQUES, António Mendo; FIGUEIREDO, Carla Cibele; PRAIA, Maria. Educação para a cidadania: cursos gerais e cursos tecnológicos 2. Lisboa: Ministério da Educação, 2001.

RAYOU, Patrick. La cité des lycéens. Paris: L’Harmattan, 1998.

RESENDE, José Manuel. A sociedade contra a escola? A socialização política escola num contexto de incerteza. Lisboa: Instituto Piaget, 2010.

RESENDE, José Manuel; DIONÍSIO, Bruno. A escola pública como “arena” política: contexto e ambivalências da socialização política escolar. Análise Social, Lisboa, v. 176, p. 661-680, out. 2005.

RESENDE, José Manuel; GOUVEIA, Luís. As artes de fazer o comum nos estabelecimentos de ensino: outras aberturas sociológicas sobre os mundos escolares. Forum Sociológico, Lisboa, v. 23, p. 97-106, 2013.

SCHILLING, Flávia; ANGELUCCI, Carla Biancha. Conflitos, violências, injustiças na escola? Caminhos possíveis para uma escola justa. Cadernos de Pesquisa, São Paulo, v. 46, n. 161, p. 694-715, jul./set. 2016.

SIMIÃO, Daniel Schroeter. Representando o corpo e violência: a invenção da "violência doméstica" em Timor-Leste. Revista Brasileira de Ciências Sociais, São Paulo, v. 21, n. 61, p. 133-45, 2006.

STAVO-DEBAUGE, Joan. L'idéal participatif ébranlé par l'accueil de l'étranger: l'hospitalité et l'appartenance en tension dans une communauté militante. Participations, v. 9, n. 2, p. 37-70, 2014.

STAVO-DEBAUGE, Joan. Qu'est-ce que l'hospitalité? Recevoir l'étranger à la communauté. Montréal: Liber, 2017.

STAVO-DEBAUGE, Joan; DELEIXHE, Martin; CARLIER, Louise. HospitalitéS: l'urgence politique et l'appauvrissement des concepts. SociologieS, 13 mar. 2018. Disponível em: http://journals.openedition.org/sociologies/6785. Acesso em: 10 ago. 2018.

THÉVENOT, Laurent. L'action au pluriel: sociologie des régimes d’engagement. Paris: La Découverte, 2006.

THÉVENOT, Laurent. Conventions for measuring and questioning policies: the case of 50 years of policy evaluations through a statistical survey. Historical Social Research, v. 36, n. 4, p. 192-217, Jan. 2011.

ZACCAÏ-REYNERS, Nathalie. Questions de respect: enquête sur les figures contemporaines du respect. Bruxelles: Éditions de l’Université de Bruxelles, 2008.

\section{NOTA SOBRE AUTORIA}

Conceção e coordenação do projeto de pesquisa - José Manuel Resende; Seleção e análise dos dados empíricos recolhidos - Luís Gouveia e David Beirante; Redação das reflexões introdutórias e conclusivas - José Manuel Resende; Revisão e edição final - José Manuel Resende, Luís Gouveia e David Beirante.

\section{COMO CITAR ESTE ARTIGO}

RESENDE, José Manuel; GOUVEIA, Luís; BEIRANTE, David. Hospitalidade e integração na arquitetura do comum nas sociabilidades escolares. Cadernos de Pesquisa, São Paulo, v. 50, n. 177, p. 641-659, jul./set. 2020. https://doi.org/10.1590/198053146808 